\title{
External beam radiation and high-dose-rate brachytherapy for elderly patients with gastroesophageal junction adenocarcinoma
}

\author{
Wei Zhang, MD!, Qifeng Wang, MD!, Tao Li, MD!, Jiahua Lv, MD', Huiming Liu, MD², Xitang Jia, MD², Bo Liu, MD², \\ Yu Fan, MD', Yi Wang, MD', Junchao Wang, MD', Lei Wu, MD', Jinyi Lang, MD, PhD' \\ IDepartment of Radiation Oncology, Sichuan Cancer Hospital \& Institution, Sichuan Cancer Center, School of Medicine, University of Electronic \\ Science and Technology of China, Chengdu, ${ }^{2}$ Department of Radiation Oncology. Changzhi Cancer Hospital, Changzhi, China
}

\begin{abstract}
Purpose: The aim of this study was to retrospectively observe and analyze the long-term treatment outcomes of 96 elderly patients with gastroesophageal junction adenocarcinoma (GEJAC) who were treated with californium-252 $\left({ }^{252} \mathrm{Cf}\right)$ neutron brachytherapy (NBT) in combination with external beam radiotherapy (EBRT) with or without chemotherapy.

Material and methods: From January 2002 to November 2012, 96 patients with GEJAC underwent treatment. The total radiation dose to the reference point via NBT was 8-25 Gy-eq in 2 to 5 fractions, with 1 fraction per week. The total dose via EBRT was 40-54 Gy, which was delivered over a period of 4 to 5.5 weeks with normal fraction.

Results: The median survival time for the 96 patients was 15.3 months, and the 1-, 2-, 3-, and 5-year rates of overall survival (OS) were $62.5 \%, 33.7 \%, 20.1 \%$, and 7.9\%, respectively. The 1-, 2-, 3-, and 5-year rates for local-regional control (LRC) were $78.7 \%, 57.9 \%, 41.8 \%$, and $26.4 \%$, respectively. The patients' age was an independent factor that was significantly associated with OS $(p=0.006)$ and LRC $(p=0.0005)$, according to univariate analysis. The 3-year OS (LRC) was $31.9 \%(62.9 \%)$ for patients aged $70-74$ years and $16.1 \%(19.5 \%)$ for patients aged $\geq 75$ years. From the time of treatment completion to the development of local-regional recurrence or death, $5(5.2 \%)$ patients experienced fistula and 7 (7.3\%) experienced massive bleeding.

Conclusions: The clinical data indicated that NBT in combination with EBRT produced favorable local control and long-term survival rates for elderly patients with GEJAC, and that the side effects were tolerable. The patient's age could be used to select the appropriate treatment in an elderly patient.

Key words: californium-252, gastroesophageal junction adenocarcinoma, late complications, neutron brachytherapy.

\section{Purpose}

Tumors of the lower esophagus and the proximal stomach are usually classified as gastroesophageal junction adenocarcinomas (GEJAC). These carcinomas are the most rapidly increasing type of tumor in many Western countries, and represent an aggressive disease with a poor prognosis $[1,2]$. In China, esophageal cancer (EC) occurs in $50.3 \%(161.3 / 320.8)$ of patients aged $60-74$, and in $19.6 \%(62.9 / 320.8)$ of patients over 75 years of age [3]. A radiation therapy oncology group study (RTOG 8501) demonstrated a survival benefit of the addition of platinum-based chemotherapy to radiation compared to radiation alone for patients with nonsurgical EC $[4,5]$. RTOG 8501 only included about $23.1 \%$ (28/121) of elderly patients ( $\geq 70$ years). Thus, the management of elderly patients with
GEJAC remains a therapeutic challenge, and the most relevant treatment modalities are still being debated. Although survival improvement has been observed over the past decade, GEJAC treatment continues to be significantly influenced by age [6]. The nonsurgical management of patients with GEJAC, including the use of laser coagulation or self-expanding metallic stents with radiation, has been considered for decades to only be a palliative modality. Despite progress in surgical practice, esophagostomy is associated with significant morbidity and mortality, and 75 is often considered the age limit for this type of surgery [7]. External beam radiation therapy (EBRT) was an important treatment strategy for elderly patients. However, a few published results indicate that EBRT combined with brachytherapy in elderly patients with EC. Recently, californium-252 $\left({ }^{252} \mathrm{Cf}\right)$ begin a clinical practice [8].
Address for correspondence: 1. Qifeng Wang, MD, Department of Radiation Oncology, Sichuan Cancer Hospital \& Institution, Sichuan Cancer Center, School of Medicine, University of Electronic Science and Technology of China, Chengdu, China, phone: +86 02885420530, fax: + 86 02885420173,

๑e-mail: littlecancer@163.com. 2. Tao Li, MD, „ e-mail: litaoxmf@126.com
Received: 03.02 .2017

Accepted: 13.07.2017

Published: 30.08 .2017 
NBT is a form of high linear energy transfer (HDR-LET) radiotherapy that has been proven to be effective for treating intracavitary cancers of the cervix when used in combination with EBRT $[9,10]$. However, for elderly patients with GEJAC or those who have refused an operation, there have yet to be any studies on the safety and usefulness of NBT in their treatment.

We performed a retrospective cohort study of 96 patients older than 69 years who were diagnosed with locally advanced GEJAC and treated with radiation therapy. The main objective was to assess the overall survival (OS) and local control rates after EBRT plus NBT for elderly GEJAC patients. We also evaluated the impact of age on treatment tolerance, prognostic factors, and patterns of failure.

\section{Material and methods \\ Patients}

From January 2002 until November 2012, a total of 96 consecutive patients older than 69 years with localized, advanced GEJAC were referred to our department at the Changzhi Cancer Hospital for radiotherapy and ${ }^{252} \mathrm{Cf}$ NBT. The reasons were as follows: 20 patients were medically inoperable (5 patients were diabetic, 13 had chronic obstructive pulmonary disease, and 2 had a prior or concurrent malignancy); 9 patients refused surgery; 7 patients were too old (75 years or older; 19 of the 47 had T4 lesions); and 41 patients had unresectable lesions. All of the 96 patients were treated with EBRT combined with brachytherapy. Patients with good performance status (at least able to care for themselves) and adequate hepatic, renal, and hematologic functions were selected for curative treatment. All of the patients had adenocarcinomas. The patients' $6^{\text {th }}$ American Joint Committee on Cancer (AJCC) stages were diagnosed as stages II to III by barium examination, endoscopy, endoscopic ultrasonography, or tumor histology. All of the patients gave their informed consent before treatment, which was in accordance with the Declaration of Helsinki, and were also approved by the Ethics Committee of Changzhi Cancer Hospital. The demographic data and tumor characteristics of each group are shown in Table 1.

\section{Radiotherapy}

Megavoltage radiation therapy units were used with a minimum source-to-axis distance of $100 \mathrm{~cm}$. The radiation field extended at least $3 \mathrm{~cm}$ superior and inferior to the tumor, with a lateral margin of at least $2 \mathrm{~cm}$. The field included the lesser curvature and bottom of the stomach if the tumor was type III [11]. The boost radiation field was the same length. Multi-field techniques were used to limit the maximum dose to the spinal cord to $\leq 45 \mathrm{~Gy}$. The radiation treatments were delivered 5 days/week at $2 \mathrm{~Gy} /$ fraction. The initial anterior-posterior parallel-opposed fields received $30 \mathrm{~Gy}$, and the off-cord fields received 20-30 Gy, for a total dose of 40-54 Gy in 20-27 fractions, over 4-5.5 weeks.

NBT with a 1-balloon applicator (Figure 1) was used in conjunction with the ${ }^{252} \mathrm{Cf}$ LZH-1000 remote after-load- ing system (Linden Science and Technology Co., Shenzhen, China). The physical characteristics of the ${ }^{252} \mathrm{Cf}$ neutron, the characteristics of the applicator, and the process of NBT were described in detail by Liu et al. $[12,13]$. The dose was prescribed to the reference point, which was located at $10 \mathrm{~mm}$ from the center point of the source capsule in the transverse direction. The number of treatment fractions of NBT was between 3 and 5 depending on the tumor regression condition at each treatment. The dose was prescribed to the reference point, located at $10 \mathrm{~mm}$ in the transverse direction from the center point of the source capsule. The total radiation dose (to the reference point) given to each patient varied between 12-20 Gy-eq in 3 to 5 fractions with 3-5 Gy-eq per fraction per week. There were 4-5 fractions administered to the adenocarcinoma patients. The treatment for each patient was, therefore, completed in 3-5 weeks. The total dose to the mucosa was estimated at 8-9 Gy-eq per fraction for adenocarcinoma. Before each NBT treatment, a different amount of X-ray contrast agent was injected into the water balloon to evaluate the tumor regression condition and to decide the additional number of treatments (or fractions) needed to complete the treatment. Figure 1 shows an X-ray image taken while the applicator and the source were both inserted into a patient's esophagus. In Figure 1, the water balloon can clearly be seen as it is filled with an X-ray contrast agent. The dose was prescribed to the reference point, which was located $10 \mathrm{~mm}$ from the center point of the source capsule in the transverse direction. The total radiation dose (to the reference point) given to each patient varied between 8 and 25 Gy-eq in 2 to 5 fractions, with 3-5 Gy-eq per fraction per week.

\section{Chemotherapy}

Whether the patient underwent chemotherapy, we chose the treatment regimens according to the patients' age, Karnofsky score (KPS), tumor types, and treatment objective. Normally, patients with KPS $\geq 80$ (37/37), stage III (34/37), and type III (20/37) GEJAC would undergo chemotherapy. Chemotherapy consisted of 3 cycles of a regimen with CDDP $\left(20 \mathrm{mg} / \mathrm{m}^{2} / \mathrm{d}\right.$ in $2 \mathrm{~h}$ infusion $)$ and $5 F U\left(500 \mathrm{mg} / \mathrm{m}^{2} / \mathrm{d}\right.$ in continuous infusion) from days 1 to 4 . The cycles were administered on days 1 and 29. MMC was given alone in a bolus injection on day 1 per week at $4 \mathrm{mg} / \mathrm{m}^{2}$. The cycles were administered on days $1,8,15$, and 22 .

\section{Toxicity assessment and follow-up}

The patients were examined weekly during the course of the EBRT. Weekly blood tests were obtained, and any admission for treatment-related complications was recorded. All adverse events were graded according to the National Cancer Institute's Common Terminology Criteria for Adverse Events (CTCAE), version 3.0 [14].

The patients usually underwent follow-up examinations every 3-4 months after the completion of treatment. Tumor response and nodal disease were evaluated with repeated computed tomography (CT) scans, barium swallow studies, and endoscopy. 
Table 1. Patient and tumor characteristics

\begin{tabular}{|c|c|c|c|c|}
\hline Characteristics & Total (\%) & $70-74$ years (\%) & $\geq 75$ years $(\%)$ & $p$ value \\
\hline \multicolumn{4}{|l|}{ Gender } & \multirow{3}{*}{0.057} \\
\hline Male & $76(79.2)$ & $35(71.4)$ & $41(87.2)$ & \\
\hline Female & $20(20.8)$ & $14(28.6)$ & $6(12.8)$ & \\
\hline \multicolumn{4}{|l|}{ KPS } & \multirow{3}{*}{0.680} \\
\hline$\geq 80$ & $47(49.0)$ & $25(51.0)$ & $22(46.8)$ & \\
\hline 70 & 49 (51.0) & $24(49.0)$ & $25(53.2)$ & \\
\hline \multicolumn{4}{|l|}{ The length } & \multirow{3}{*}{0.990} \\
\hline$\leq 3 \mathrm{~cm}$ & $45(46.9)$ & $23(46.9)$ & $22(46.8)$ & \\
\hline$>3 \mathrm{~cm}$ & $51(53.1)$ & $26(53.1)$ & $45(53.2)$ & \\
\hline \multicolumn{4}{|l|}{ Tumor location } & \multirow{4}{*}{0.795} \\
\hline Type I & $5(5.2)$ & $3(6.1)$ & $2(4.3)$ & \\
\hline Type II & $50(52.1)$ & $24(49.0)$ & $26(55.3)$ & \\
\hline Type III & $41(42.7)$ & $22(44.9)$ & $19(40.4)$ & \\
\hline \multicolumn{4}{|l|}{ T stage } & \multirow{4}{*}{0.902} \\
\hline $\mathrm{T} 2$ & $20(20.8)$ & $10(20.4)$ & $10(21.3)$ & \\
\hline T3 & $35(36.5)$ & $17(34.7)$ & $18(38.3)$ & \\
\hline $\mathrm{T} 4$ & $41(42.7)$ & $22(44.9)$ & $19(40.4)$ & \\
\hline \multicolumn{4}{|l|}{ N stage } & \multirow{3}{*}{0.738} \\
\hline NO & 26 (27.1) & $14(28.6)$ & $12(25.5)$ & \\
\hline N1 & 70 (72.9) & $35(71.4)$ & $35(74.5)$ & \\
\hline \multicolumn{4}{|l|}{$6^{\text {th }}$ AJCC stage } & \multirow{3}{*}{0.911} \\
\hline II & $25(26.0)$ & $13(26.5)$ & $12(25.5)$ & \\
\hline III & $71(74.0)$ & $36(73.5)$ & $35(74.5)$ & \\
\hline \multicolumn{4}{|l|}{ Chemotherapy } & \multirow{3}{*}{0.962} \\
\hline Yes & 37 (38.5) & 19 (38.8) & 18 (38.3) & \\
\hline No & 59 (61.5) & $30(61.2)$ & $29(61.7)$ & \\
\hline \multicolumn{4}{|l|}{ RT dose } & \multirow{3}{*}{0.493} \\
\hline$\leq 66 \mathrm{~Gy}$ & $36(37.5)$ & $20(40.8)$ & $16(34.0)$ & \\
\hline$\geq 67$ Gy & $60(62.5)$ & $29(59.2)$ & $31(66.0)$ & \\
\hline
\end{tabular}

$R T$ - radiotherapy alone, OS - overall survival, LCR - local control rate, KPS - Karnofsky performance score, AJCC - American Joint Committee on Cancer

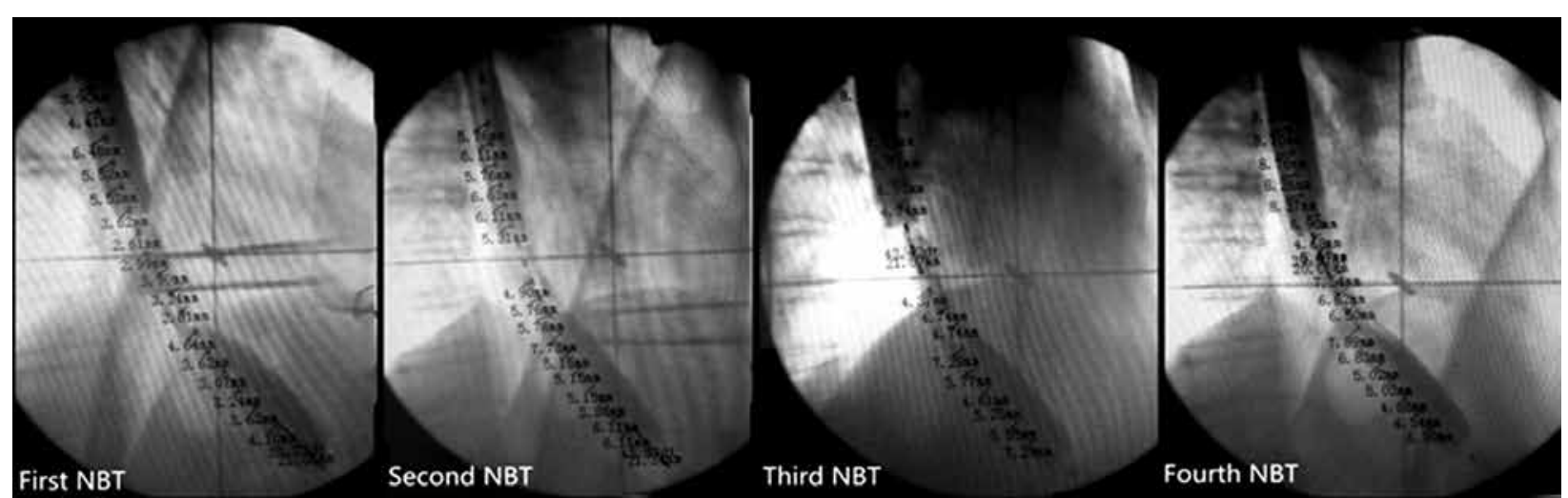

Fig. 1. Images (first-fourth NBT) showing the tumor regression conditions before each of the 4 neutron brachytherapy treatments under an X-ray treatment-planning simulator 


\section{Statistical analysis}

The objectives of the study were to evaluate overall acute toxicity and local-regional control rates. Death from esophageal cancer was considered a treatment failure in the survival analysis. Survival was calculated from the date of consultation until death or the last follow-up evaluation. The pattern of failure (local and/or regional vs. distant) was defined as the first site of failure. The time to first failure, time to any local failure, and time to any distant metastases were calculated from the date of consultation. Local and regional recurrence included the primary tumor and regional lymph nodes. Overall survival and local-regional control were estimated using the Kaplan-Meier method. Pearson's $\chi^{2}$ test was used to assess measures of association in the frequency data. A value of $p<0.05$ was considered statistically significant.

\section{Results}

\section{Patient characteristics and treatments}

The ages of the GEJAC patients who were treated with radiation therapy (NBT and EBRT) ranged from 70 to 84 years (median, 75 years). Among the 96 cases, 49 were aged $70-74$ and 47 were aged $\geq 75$ years. The cancer stages were categorized according to the $6^{\text {th }}$ Edition of the AJCC Cancer Staging Manual, with 25 patients categorized as stage II and 71 categorized as stage III. The pathologic differentiation grades (PDG) were adenocarcinoma without pathological differentiation $64(66.6 \%)$, and well, medium, and poor PDG were 2,16, and 14, respectively. The detailed patient data and log-rank test are provided in Table 1.

\section{Prognostic factors for overall survival and local-regional control}

The duration of follow-up ranged from 6 to 106 months (median, 30.4 months). The median survival time for the 96 patients was 15.3 months, and the 1-, 2-, 3-, and 5-year rates for OS were $62.5 \%, 33.7 \%, 20.1 \%$, and $7.9 \%$, respectively. The 1-, 2-, 3-, and 5-year rates for local-regional control (LRC) were $78.7 \%, 57.9 \%, 41.8 \%$, and $26.4 \%$, respectively.

\section{A}

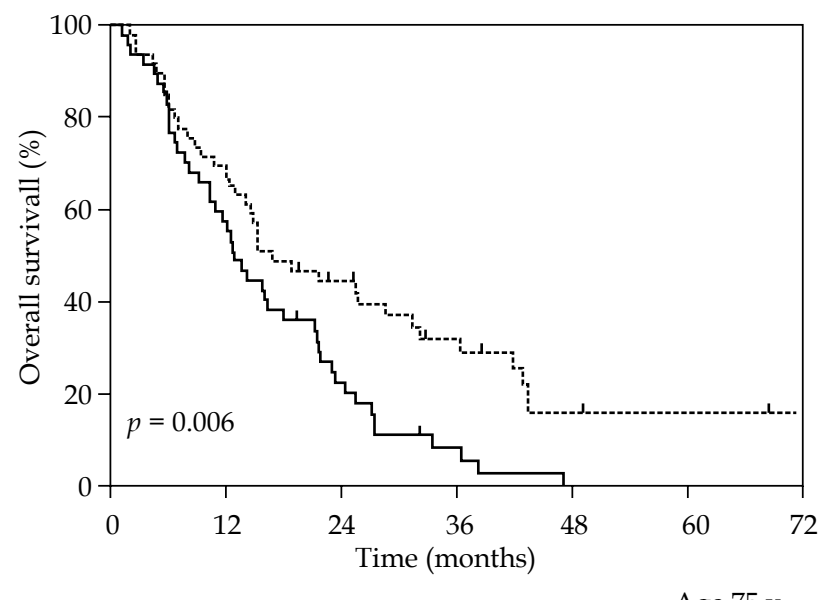

- Age $75 \mathrm{y}$
We used the following factors for the univariate analysis of survival rates and the local control rate: sex, age, KPS, tumor type, tumor length, tumor $\mathrm{T}$ stage, nodal stage, clinical stage, chemotherapy, and radiation dose. Among them, age was found to have relevance to OS $(p=0.006)$. Age was the only factor that significantly related to LRC ( $p=0.0005)$. In the univariate analysis, the 3-year OS (LRC) was $31.9 \%(62.9 \%)$ for patients aged $70-74$ years and $16.1 \%(19.5 \%)$ for patients aged $\geq 75$ years $(p=0.006$ and $p=0.0005$, respectively; Figures $2 \mathrm{~A}$ and B). A total of 37 patients underwent concurrent chemotherapy. Otherwise, chemotherapy combined with NBT + EBRT did not lead to a significant improvement of the OS than the RT alone.

\section{Patterns of failure}

At the time of the analysis (May 2013), 13 patients were alive and free of disease, and 5 were alive with disease evolution. Distant metastases occurred in 16 patients $(16.7 \%)$. The median time to developing distant metastases was 8.9 months. The main sites of distant metastases were the lung $(n=5)$, liver $(n=1)$, brain $(n=1)$, and bones $(n=2)$. In 7 patients, metastases developed in more than 1 organ. Additionally, 18 patients died of mixed causes, including pneumonia, cerebral hemorrhage, and heart infarction. Local-regional recurrence occurred in 42 (42/96, $43.8 \%$ ) patients, with $32 / 42(76.2 \%)$ occurrences outside the radiation fields and 10/42 (23.8\%) occurrences inside the radiation fields. Patients $\geq 75$ years $(27 / 96,28.1 \%)$ had increased LRC significantly more than those in the 70-74 years group $(15 / 96,15.6 \%, p=0.008)$. For out-field LRC, patients $\geq 75$ years $(22 / 96,22.9 \%)$ had increased LRC significantly more than those in the 70-74 years group $(10 / 96,10.4 \%, p=0.006)$. Additionally, $7 / 42$ had primary tumor recurrences. None of those patients underwent salvage surgery.

\section{Treatment toxicity}

All 96 patients completed the planned NBT and EBRT treatments. In terms of acute toxicity (graded according

\section{B}

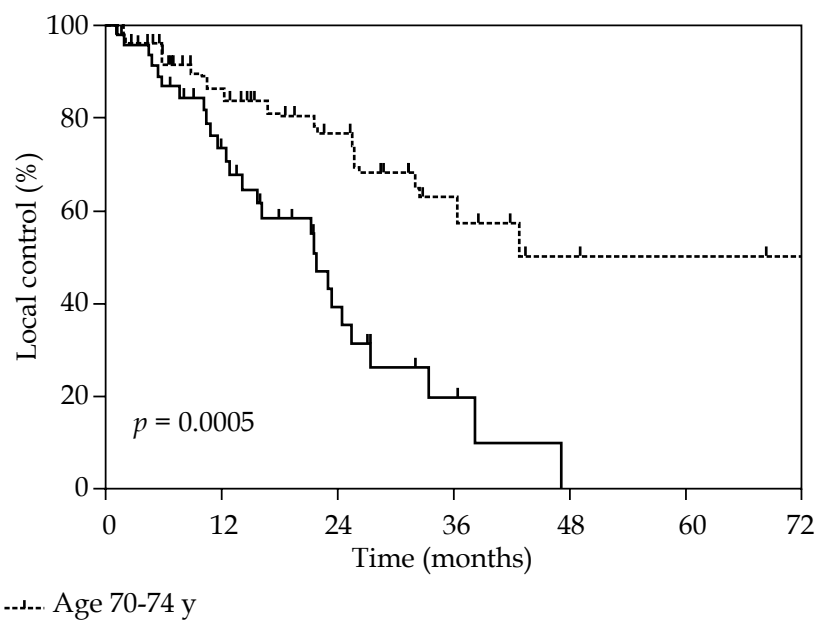

Fig. 2. Comparison of the overall survival rate $(\mathbf{A})$ and the local control rate $(\mathbf{B})$ between the 2 age groups 
to the National Cancer Institute's Common Terminology Criteria for Adverse Events, version 3.0), no perforations were observed during this treatment period. In total, $73(76.0 \%)$ patients developed Grade 2 hematologic toxicity. Dysphagia was relieved after the second or third NBT treatment in $49 \%$ of the patients, and a temporary feeding tube was not required in most of the patients. Grade $\geq 2$ esophagitis, expressed by clinical odynophagia, was observed in 46 cases (47.9\%), and was managed with the early introduction of $\mathrm{H}_{2}$ blockers and surface anesthesia at the initiation of NBT. In total, 4 (4.1\%) patients had Grade $\geq 2$ irradiation dermatitis. From the time of treatment completion to the development of localregional recurrence or death, 5 (5.2\%) and 7 (7.3\%) patients experienced fistulas and massive bleeding, respectively. As shown in Table 2, the incidence of severe, late complications was not related to older age. In total, $69.8 \%$ of the patients resumed normal swallowing, while $6.3 \%$ had some residual dysphagia (non-malignant stenosis) requiring intermittent dilatation.

As shown in Table 3, patients who received both radiotherapy (NBT + EBRT) and chemotherapy did not have a significant increase in acute and late toxicities compared to radiotherapy alone.

\section{Discussion}

To our knowledge, this is the first reported clinical experience using NBT and EBRT for elderly patients with GEJAC. The safety and efficacy of this comprehensive treatment appear promising. We also found that, firstly, NBT + EBRT is safe and beneficial in terms of local control in the radical treatment of elderly patients with GEJAC, and secondly, the OS rate was significantly increased and the late complication rate was significantly decreased in patients aged 70-74 years compared to patients aged $\geq 75$ years. No severe acute complications were reported during the treatment time.

In the current study, the results in terms of OS and progression-free survival (PFS) are consistent with those published in the literature, notably in the largest cohort of 109 elderly patients treated with exclusive adjuvant radiochemotherapy (RCT) with a median OS and PFS of 15.2 and 8.3 months, respectively $[15,16,17]$. Rochigneux reported that age is an important prognostic factor for elderly patients undergoing treatment [16]. In our study, the best results in terms of OS were obtained for patients aged 70-74 years, and age was the only prognostic factor for OS and LRC.

Table 2. Treatment toxicity and the sites of first failure according to different age groups

\begin{tabular}{|c|c|c|c|}
\hline Characteristics & $70-74$ years $(n=49)$ & $\geq 75$ years $(n=47)$ & $p$ value \\
\hline \multicolumn{4}{|l|}{ Acute toxicity } \\
\hline Esophagitis & $24(25.0 \%)$ & $22(22.9 \%)$ & 0.831 \\
\hline Skin complications & $2(2.1 \%)$ & $4(4.2 \%)$ & 0.571 \\
\hline Pulmonary complications & $1(1.0 \%)$ & $3(3.1 \%)$ & 0.287 \\
\hline Leukopenia & $36(37.5 \%)$ & $37(38.5 \%)$ & 0.547 \\
\hline Neutropenia & $24(25.0 \%)$ & $23(24.0 \%)$ & 0.997 \\
\hline Thrombocytopenia & $5(10.2 \%)$ & $6(6.3 \%)$ & 0.694 \\
\hline \multicolumn{4}{|l|}{ Late toxicity } \\
\hline Esophageal fistulas & $4(4.2 \%)$ & $1(1.0 \%)$ & 0.183 \\
\hline Massive bleeding & $3(3.3 \%)$ & $4(4.3 \%)$ & 0.694 \\
\hline \multicolumn{4}{|l|}{ The sites of first failure in the whole group } \\
\hline Local-regional failure & $15(15.6 \%)$ & $27(28.1 \%)$ & 0.008 \\
\hline In field & $5(5.2 \%)$ & $5(5.2 \%)$ & 0.134 \\
\hline Out field & $10(10.4 \%)$ & $22(22.9 \%)$ & 0.006 \\
\hline Distant metastasis & $9(18.3 \%)$ & 7 (13.1\%) & 0.847 \\
\hline Lung & $2(4.1 \%)$ & $3(6.4 \%)$ & 0.612 \\
\hline Liver & $2(4.1 \%)$ & 0 & 0.162 \\
\hline Bone & $2(4.1 \%)$ & 0 & 0.162 \\
\hline Brain & $1(2.0 \%)$ & 0 & 0.325 \\
\hline$\geq 2$ metastasis sites & $3(6.1 \%)$ & $4(8.5 \%)$ & 0.653 \\
\hline $\begin{array}{l}\text { Not otherwise specified (disease of heart, } \\
\text { head blood-vessel, pneumonia, second tumor) }\end{array}$ & $11(4.3 \%)$ & 7 (17.9\%) & 0.690 \\
\hline
\end{tabular}


Table 3. Treatment toxicity according to radiotherapy (neutron brachytherapy and external beam radiotherapy) versus radiotherapy (neutron brachytherapy and external beam radiotherapy) and chemotherapy

\begin{tabular}{|c|c|c|c|}
\hline Characteristics & $\begin{array}{c}\mathrm{NBT}+\mathrm{EBRT}+\mathrm{CT} \\
n=37\end{array}$ & $\begin{array}{c}\mathrm{NBT}+\mathrm{EBRT} \\
n=59\end{array}$ & $p$ value \\
\hline \multicolumn{4}{|l|}{ Acute toxicity } \\
\hline Esophagitis & $18(48.6 \%)$ & $26(44.1 \%)$ & 0.831 \\
\hline Skin complications & $2(5.4 \%)$ & $4(6.8 \%)$ & 0.575 \\
\hline Pulmonary complications & $1(2.7 \%)$ & $3(5.1 \%)$ & 0.499 \\
\hline Leukopenia & $19(51.4 \%)$ & $28(47.5 \%)$ & 0.436 \\
\hline Neutropenia & $29(78.4 \%)$ & $44(74.6 \%)$ & 0.433 \\
\hline Thrombocytopenia & $5(13.5 \%)$ & $6(10.2 \%)$ & 0.694 \\
\hline \multicolumn{4}{|l|}{ Late toxicity } \\
\hline Esophageal fistulas & $3(8.1 \%)$ & $2(3.4 \%)$ & 0.288 \\
\hline Massive bleeding & $1(2.9 \%)$ & $6(10.3 \%)$ & 0.191 \\
\hline
\end{tabular}

$C T$-chemotherapy, NBT - neutron brachytherapy, ERBT-external beam radiotherapy

Table 4. Comparative toxicity rates, overall survival, and local control of selected series

\begin{tabular}{|c|c|c|c|c|c|c|}
\hline Authors (Ref.) & $\begin{array}{l}\text { Hishikawa, } \\
\text { et al. [20] }\end{array}$ & $\begin{array}{l}\text { Flores, } \\
\text { et al. [21] }\end{array}$ & $\begin{array}{l}\text { Hareyama, } \\
\text { et al. [22] }\end{array}$ & $\begin{array}{c}\text { Tao Li, } \\
\text { et al. [23] }\end{array}$ & $\begin{array}{c}\text { RTOG 92-07 } \\
\text { [19] }\end{array}$ & Present study* \\
\hline No. of pts. & 148 (66\# pts) & 145 & 161 & 191 & 50 & 96 \\
\hline BT Gy/fraction & $12 / 2$ & $15 / 1$ & $15-20 / N S$ & $12-25 / 2-6$ & $15 / 3$ & $12-25 / 2-6$ \\
\hline ERT Gy/fraction & $60 / 30$ & $40 / 15$ & $47-70 / 25-35$ & $40-60$ & 50 & $40-60$ \\
\hline $\mathrm{CT}(\mathrm{pts})$ & No & No & No & $191 / 191$ & Yes & $37 / 96$ \\
\hline Fistula (\%) & 5.3 & 5 & 1.2 & 2.6 & 12 & $5(5.2 \%)$ \\
\hline Bleeding (\%) & 0 & 11 & 0 & 7.9 & NS & $7(7.4 \%)$ \\
\hline Ulcer (\%) & 7.1 & NS & 3 & 2.6 & NS & 0 \\
\hline Stricture (\%) & 10 & 35 & 3 & 4.2 & 4 & $6(6.3 \%)$ \\
\hline Death rate (\%) & 3 & 0.6 & 0 & 0 & 8 & 0 \\
\hline OS (\%) & 37 (2 y) (66\# pts) & $\begin{array}{l}26(2 y) \\
19(3 y)\end{array}$ & $\begin{array}{l}43.3 \text { - stage I }(5 \text { y) } \\
21.1 \text { - stage II }(5 \text { y) }\end{array}$ & $36.3(3 y)$ & $48(1 \mathrm{y})$ & $20.1(3 y)$ \\
\hline LC (\%) & 64 (2 y) (66\# pts) & NS & $31.7 \%(5 y)$ & $75.6(3 y)$ & $58(1 \mathrm{y})$ & $41.8(3 y)$ \\
\hline
\end{tabular}

CT - chemotherapy, BT - brachytherapy, ERBT - external beam radiotherapy, Pts - patients, NS - not stated, OS - overall survival, LD - limited disease, LC - local control

*Brachytherapy given between EBRT

We believe that there are at least 2 factors that made the ${ }^{252} \mathrm{Cf}$-based NBT more effective for local tumors than chemotherapy regimens, particularly in the treatment of locally advanced GEJAC. The first factor is related to the high-LET nature of fission neutrons, which made them much more effective (compared to the low-LET X-ray) in killing the hypoxic tumor cells in the locally advanced cancers. The second factor is related to the fact that water is an effective neutron attenuator that can be conveniently injected into the source applicator during treatment to reduce the neutron dose to the nearby normal tissue. Because there is a significant difference in the elasticity of normal tissue and tumor tissue, the proper injection of water into the source applicator can effectively push away the nearby normal tissue, while keeping the tumor tissue close to the source. Then the water is an neutron ray protector. We estimate that $1 \mathrm{~cm}$ of water can reduce neutron dose by approximately $15 \%$.

Concerning RCT tolerance, Tougeron reported that age $\geq 75$ years was associated with worse creatinine clearance $(p<0.01)$ and greater chemotherapy dose reduction at treatment onset due to age $(p<0.01)$, but this had no influence on the total CRT dose or OS [18]. In the current study, the incidence of late severe complications was significantly related to the factors of higher total dose and brachytherapy dose. In addition to the dose factors, the patients' age also significantly increased the incidence of relevant, late complications. While the normally expected 
side effects (shown in Table 2) seem to be quite acceptable, the number of deaths $(n=20$ or $10.5 \%)$ resulting from fistula, hematemesis, and hemoptysis was high. This may be linked to the late effect of radiation damage, as fatal esophagitis of fistula cases were also observed in the RTOG 92-07 trial where the ${ }^{192}$ Ir-based HDR boost dose of 15 Gy in 3 weekly fractions was deemed to be too high [19]. However, they could also have been caused by local recurrences of the cancer. From Table 4, with increased age, the severe acute and late treatment-related toxicities were not significantly increased [20,21,22,23]. Further CT review is needed to compare the pretreatment tumor length, the esophageal tumor wall thickness, and the association of tumor with surrounding normal structures with subsequent fistula formation.

Compared to published data, our population was more homogeneous regarding age, pathological type, and tumor location as we chose an inferior limit at 70 years instead of 65 . Furthermore, patients were selected for PS or comorbidity, similar to the study of Anderson et al., in which only patients with Karnofsky index $>70 \%$ were included. Consequently, our population can be considered as representative of routine clinical practice.

The major limitation of our study was that the retrospective analysis might have been based on incomplete medical records. Other limitations were that the study was conducted in a single institution, the sample size was small, and there was a lack of predefined factors determining treatment decisions, which were based only on evaluations by the referral doctor and members of a multidisciplinary team. The aim of the study was to retrospectively identify the parameters to be associated with the key therapeutic decisions.

\section{Conclusions}

Our results suggest that elderly patients with GEJAC could benefit from NBT + EBRT without major toxicities. Its outcome is close to younger patient outcomes published in the literature. This emphasizes the fact that curative treatments for GEJAC should not be rejected based only on a patient's age.

\section{Acknowledgments}

The authors gratefully thank Professor C.-K. Chris Wang for assistance.

\section{Disclosure}

Authors report no conflict of interest.

\section{Funding}

This work was supported by the Sichuan Province's selected excellent projects for foundation from the science and technology projects in 2016.

\section{References}

1. Siegel RL, Jemal A. Cancer Facts \& Figures. American Cancer Society, Inc., Atlanta 2013.
2. Chen $\mathrm{W}$, Zheng R, Baade PD et al. Cancer statistics in China, 2015. CA Cancer J Clin 2016; 66: 115-132.

3. Zeng H, Zheng R, Zhang $S$ et al. Esophageal cancer statistics in China, 2011: Estimates based on 177 cancer registries. Thorac Cancer 2016; 7: 232-237.

4. Herskovic A, Martz K, al-Sarraf M et al. Combined chemotherapy and radiotherapy compared with radiotherapy alone in patients with cancer of the esophagus. N Engl J Med 1992; 326: 1593-1598.

5. Cooper JS, Guo MD, Herskovic A et al. Chemoradiotherapy of locally advanced esophageal cancer: long-term follow-up of a prospective randomized trial (RTOG 85-01). Radiation Therapy Oncology Group. JAMA 1999; 281: 1623-1627.

6. Bouvier AM, Launoy G, Lepage C, Faivre J. Trends in the management and survival of digestive tract cancers among patients aged over 80 years. Aliment Pharmacol Ther 2005; 22: 233-241.

7. Law S, Wong KH, Kwok KF et al. Predictive factors for postoperative pulmonary complications and mortality after esophagectomy for cancer. Ann Surg 2004, 240: 791-800.

8. Wang C-KC. Progress in californium-252 neutron brachytherapy. In: Brachytherapy. Kishi K (ed.). InTech 2012.

9. Maruyama Y, van Nagell JR, Yoneda J et al. A review of californium-252 neutron brachytherapy for cervical cancer. Cancer 1991; 68: 1189-1197.

10. Lei X, Qian CY, Qing Y et al. Californium-252 brachytherapy combined with external-beam radiotherapy for cervical cancer: long-term treatment results. Int J Radiat Oncol Biol Phys 2011; 81: 1264-1270.

11. Siewert JR, Stein HJ. Classification of adenocarcinoma of the oesophagogastric junction. Br J Surg 1998; 85: 1457-1459.

12. Liu H, Wang Q, Jia $X$ et al. Early-stage esophageal squamous cell carcinoma treated with californium-252 neutron brachytherapy: clinical report on 16 cases. Tumori 2013; 99: 172-175.

13. Liu H, Wang Q, Wan X et al. Californium-252 neutron brachytherapy combined with external beam radiotherapy for esophageal cancer: long-term treatment results. Brachytherapy 2014; 13: 514-521.

14. Common Terminology Criteria for Adverse Events, 2006: Available at: http://ctep.cancer.gov/protocolDevelopment/ electronic_applications/docs/ctcaev3.pdf. Accessed: 5 October 2009.

15. Tougeron D, Di Fiore F, Thureau S et al. Safety and outcome of definitive chemoradiotherapy in elderly patients with oesophageal cancer. Br J Cancer 2008; 99: 1586-1592.

16. Rochigneux P, Resbeut M, Rousseau F et al. Radio(chemo) therapy in Elderly Patients with Esophageal Cancer: A Feasible Treatment with an Outcome Consistent with Younger Patients. Front Oncol 2014; 4: 100.

17. Anderson SE, Minsky BD, Bains $M$ et al. Combined modality chemoradiation in elderly oesophageal cancer patients. Br J Cancer 2007; 96: 1823-1827.

18. Tougeron D, di Fiore F, Thureau S et al. Safety and outcome of definitive chemoradiotherapy in elderly patients with oesophageal cancer. Br J Cancer 2008; 99: 1586-1592.

19. Gaspar EL, Qian C, Kocha WI et al. A phase I/II study of external beam radiation, brachytherapy, and concurrent chemotherapy in localized cancer of the esophagus (RTOG 92-07):preliminary toxicity report. Int J Radiation Oncology Biol Phys 1997; 37: 593-599.

20. Hishikawa Y, Kurisu K, Taniguchi M et al. High-dose-rate intraluminal brachytherapy for esophageal cancer: 10 years' experience in Hyogo College of Medicine. Radiother Oncol 1991; 21: 107-114.

21. Flores AD, Nelems B, Evans $K$ et al. Impact of new radiotherapy modalities on the surgical management of cancer of 
the esophagus and cardia. Int J Radiat Oncol Biol Phys 1989; 17: 937-944.

22. Hareyama M, Nishio M, Kagami $\mathrm{Y}$ et al. Intracavitary brachytherapy combined with external-beam irradiation for squamous cell carcinoma of the thoracic esophagus. Int J Radiat Oncol Biol Phys 1992; 24: 235-240.

23. Li T, Zhang W, Lv J et al. Safety and outcome of external beam radiation and neutron brachytherapy in elderly patients with esophageal squamous cell cancer. J Contemp Brachytherapy 2017; 9: 36-43. 